\title{
Effect of acid leaching of bamboo and hardwood chips on kraft pulping and pulp bleaching
}

\author{
M. Sarwar Jahan ${ }^{1}$, S. Islam², M. Moniruzzaman ${ }^{3}$ and M. A. Quaiyyum² \\ ${ }^{I}$ Pulp and Paper Research Division, BCSIR Laboratories, Dhaka, Dr. Qudrat-i-Khuda Road \\ ${ }^{2}$ Department of Applied Chemistry and Chemical Engineering, University of Dhaka, Dhaka- 1000 \\ ${ }^{3}$ Soil \& Environment Research Division, BCSIR Laboratories, Dhaka, Dr. Qudrat-i-Khuda Road
}

\begin{abstract}
Acid leaching of chips prior to pulping is a proven method to reduce non-process elements in kraft pulping process. In this paper, acid leaching of bamboo and hardwood chips was carried out at $\mathrm{pH} 2$ for $1 \mathrm{~h}$ at $80{ }^{\circ} \mathrm{C}$ prior to kraft pulping. Calcium removal in acid leaching from wood chips was $52.6 \%$ while for bamboo was only $17.4 \%$. Acid leaching also reduced potassium (K) from $1258 \mathrm{mg} / \mathrm{kg}$ to $495.7 \mathrm{mg} / \mathrm{kg}$ for bamboo and $928 \mathrm{mg} / \mathrm{kg}$ to $562.5 \mathrm{mg} / \mathrm{kg}$ for wood chips. The effects of acid leaching on pulping, pulp bleaching, and papermaking characteristics were also determined. Acid leaching of both kinds of chips prior to kraft cooking resulted in a significant increase in the rate of delignification. Acid leached chips showed higher screen pulp yield and lower rejects at any kappa number. There was no significant difference of papermaking properties between pulps obtained from acid leached and non-leached chips. Using same $\mathrm{ClO}_{2}$ charge, acid leaching improved pulp brightness by $1 \%$ and $1.1 \%$ for hardwood and bamboo, respectively. Acid leaching improved pulp viscosity from 10.1 mP.s to $12.1 \mathrm{mP} . \mathrm{s}$ for hardwood.
\end{abstract}

Keywords: Bamboo and hardwood chips; Acid leaching; Pulp yield; Pulp bleaching

\section{Introduction}

Most of the non-process elements (NPEs) usually come to the process through wood chips, make-up chemicals, makeup lime (Rocha et al., 1998; Taylor and McGuffie, 2006; Ulmgren,1987) process water, bleaching chemicals, and with recycled effluent streams and biosludge (Tran and Vakkilainen, 2007). However, close system tends to limit some NPEs. Accumulation of NPEs in the pulping process may cause deposits/corrosion in the liquor recovery cycle and in various parts of the bleach plant, such as washer screens, filtrate tanks, nozzles, repulpers, pumps, piping and instrumentation and can affect bleaching chemical consumption, especially when hydrogen peroxide is used.

Transition metals participate in a large number of chemical oxidations capable of pulp color formation (Colodette et al., 1989a; Colodette et al., 1989b). Transition metals-catalyzed decomposition of hydrogen peroxide results in reagent loss and formation of free radicals that degrade cellulose. Since peroxide is also generated during bleaching with oxygen, the presence of transition metals, especially iron, manganese and copper is undesirable during this stage.
It is found that acid leaching of wood chips is a promising technology for reducing NPEs in kraft pulping,consequently increasing the rate of delignification, unbleached pulp brightness and improve pulp bleachability (DelAntonio et al., 2011; Lundqvist et al., 2006). Recently Santose et al. (2015) also showed that acid leaching of eucalyptus wood chips considerably reduced NPEs. Humar et al. (2004) leached chromate-copper-borate treated wood sample using five different agents, namely, water, an aqueous solution of oxalic or acetic acid, and an aqueous solution of oxalic or acetic acid with ammonia. The highest chromium leaching was achieved with the aqueous solution of oxalic acid.

Kharnaphuli Paper Mills (KPM)- only pulp mill in Bangladesh has recently installed oxygen delignification plant. Bamboo and mixed hardwoods are are used in this mill. No study has been made on the NPEs of these raw materials. Therefore, in this study acid leaching of industrial chips of bamboo and mixed hardwoods was carried out with acidic water. The main objectives were to determine the impact of acid leaching on the kraft pulping and bleaching.

*Corresponding author e-mail: sarwar2065@hotmail.com 


\section{Materials and methods}

Raw materials

Bamboo and mixed hardwood chips were collected from the KPM for acid leaching and subsequent pulping experiment.

\section{Acid leaching}

The acid leaching experiment of bamboo and mixed hardwood chips was carried out separately by acidic water in polyethylene bag. The chips $(250 \mathrm{~g}$ od basis) were treated with sulfuric acid-water under the following conditions: 1:10 material to liquor ratio, $80{ }^{\circ} \mathrm{C}, 60 \mathrm{~min}$ and $\mathrm{pH}$ 2.0. After acid leaching, the liquor was collected for NPEs determination and chips were washed with distilled water.

\section{Pulping}

Acid leached and non-leached bamboo and mixed hardwood chips were used for subsequent pulping experiment. Pulping was carried out by kraft process in a thermostatically controlled electrically heated digester with capacity of 5 litres. Pulping conditions were as follows:

-Active alkali was 16, 18 and $20 \%$ on oven-dry (o.d) raw material as $\mathrm{Na}_{2} \mathrm{O}$

-Cooking time was fixed for $2 \mathrm{~h}$ at maximum temperature $\left(170{ }^{\circ} \mathrm{C}\right.$ ), with $90 \mathrm{~min}$ to raise maximum temperature $\left(170^{\circ} \mathrm{C}\right)$ from room temperature.

-Liquor to material ratio was 4.

-Sulphidity $25 \%$ for kraft process.

After digestion, pulp was washed until free from residual chemicals, and screenedin a flat vibratory screener (Yasuda, Japan). The screened pulp yield, total pulp yield and screened reject were determined gravimetrically as percentage of o.d. raw material. The kappa number (T 236 om-99) of the resulting pulp was determined in accordance with Tappi Test Methods. Three replicates of all experiments were done and average reading was taken.

\section{Evaluation of pulps}

Pulps were beaten in a PFI mill to get drainage resistance ( $\left.{ }^{\circ S R}\right) 25$ and hand sheets of about $60 \mathrm{~g} / \mathrm{m}^{2}$ were made in a Rapid Kothen sheet making machine. The sheets were tested for tensile (T 494 om-96), burst (T 403 om-97) and tear strength (T 414 om-98) according to TAPPI Standard Test Methods.

\section{DEpD bleaching}

The acid leached and non-leached bamboo and mixed hardwood pulps were bleached by $\mathrm{D}_{0} \mathrm{EpD}_{1}$ bleaching sequences (where D represents chlorine dioxide and Ep represents peroxide reinforced alkaline extraction). The $\mathrm{ClO}_{2}$ charge was $2 \%$ and temperature was $70^{\circ} \mathrm{C}$ for $45 \mathrm{~min}$ in the $\mathrm{D}_{0}$ stage. The $\mathrm{pH}$ was adjusted to 2.5 by adding dilute $\mathrm{H}_{2} \mathrm{SO}_{4}$. Alkaline extraction was carried out with $2 \% \mathrm{NaOH}$ and $0.5 \%, \mathrm{H}_{2} \mathrm{O}_{2}$ charge, temperature was $70^{\circ} \mathrm{C}$ for $120 \mathrm{~min}$. In the $\mathrm{D}_{1}$ stage, $\mathrm{ClO}_{2}$ charge were $0.5, \mathrm{pH}$ was adjusted to 4.5 by adding dilute alkali. The pulp consistency was $10 \%$ in all the stages. The brightness (T 452 om-92) and viscosity (T 230 om-99) of the bleached pulp were determined in accordance with Tappi Test Methods.

\section{NPEs determination}

NPEs were determined by atomic adsorption spectophotometer at the soil science laboratory of BCSIR Laboratories, Dhaka.

\section{Results and discussion}

\section{Acid leaching}

Acid leaching may cause acid hydrolysis of carbohydrate consequently decrease pulp yield and strength properties in subsequent pulping. Axegard (2003) showed that acid hydrolysis of carbohydrate leaching was minimum at temperature lower than $100{ }^{\circ} \mathrm{C}$ and no negative effect of strength properties of pulp. It was also observed that considerable amount of NPEs were removed from wood chips by leaching at $\mathrm{pH} 2-3$. Therefore, in this study, acid leaching was carried out at $80{ }^{\circ} \mathrm{C}$ with $\mathrm{pH} 2$.

Acid leaching of bamboo and hardwood chips resulted in weight loss of 2.1 and $2.0 \%$, respectively. The composition of the organic material lost was not determined. Acid leaching results are shown in Table I. As shown in Table I, acid leaching efficiently removed metals from the bamboo and hardwood chips and contributed to improving chips characteristics prior to pulping. Leaching resulted in reduction potassium (K) from $1258 \mathrm{mg} / \mathrm{kg}$ to $495.7 \mathrm{mg} / \mathrm{kg}$ for bamboo 
Table I. Effect of acid leaching on the non process elements of bamboo and wood

\begin{tabular}{|c|c|c|c|c|c|c|}
\hline \multirow[t]{2}{*}{ NPEs } & \multicolumn{3}{|c|}{ Bamboo } & \multicolumn{3}{|c|}{ Wood } \\
\hline & $\begin{array}{c}\text { Without } \\
\text { Leaching }(\mathrm{mg} / \mathrm{kg})\end{array}$ & $\begin{array}{c}\text { On } \\
\text { Leaching }(\mathrm{mg} / \mathrm{kg})\end{array}$ & $\begin{array}{c}\% \\
\text { removal }\end{array}$ & $\begin{array}{c}\text { Without Leaching } \\
(\mathrm{mg} / \mathrm{kg})\end{array}$ & $\begin{array}{c}\text { On Leaching } \\
(\mathrm{mg} / \mathrm{kg})\end{array}$ & $\%$ removal \\
\hline $\mathrm{Ca}$ & 223 & 185 & 17.4 & 721 & 342.1 & 52.6 \\
\hline $\mathrm{Mg}$ & 325 & 253 & 22.2 & 443 & 304.9 & 31.1 \\
\hline $\mathrm{Fe}$ & 48.3 & 14.7 & 69.6 & 48.8 & 6.3 & 87.1 \\
\hline $\mathrm{Mn}$ & 60.2 & 29.3 & 51.3 & 16.84 & 4.7 & 72.1 \\
\hline $\mathrm{K}$ & 1258 & 495.7 & 60.6 & 928 & 562.5 & 39.4 \\
\hline
\end{tabular}

and $928 \mathrm{mg} / \mathrm{kg}$ to $562.5 \mathrm{mg} / \mathrm{kg}$ for wood chips, which accounted $60.6 \%$ and $39.4 \%$, respectively. $\mathrm{K}$ impacts negatively on thermal properties of recovery boiler deposits and even in small quantities can accelerate obstruction of flue gas passages by reducing deposit melting point (Ulmgren, 1997).

Calcium removal in acid leaching from wood chips was $52.6 \%$, while for bamboo was only $17.4 \%$. Presence of calcium favors formation of calcium oxalate, one of the hardest and most difficult deposits to remove (Silva et al., 2002). Furthermore, calcium carbonate $\left(\mathrm{CaCO}_{3}\right)$ found in industrial white liquor can increase deposit formation problems in the digester. Even at low concentrations, $\mathrm{CaCO}_{3}$ readily precipitates in white liquor storage tanks, forming deposits that can be carried over to the cook. Additionally, reduction in black liquor soluble calcium will avoid super concentration of sodium salts in the first effects of the evaporation plant. This in turn will impede massive precipitation of salts such as sodium bicarbonate that can cause deposits, reduce heat exchange coefficients and compromise plant operations (Verrill and Frederick, 2005). It has also been suggested that calcium may have a negative effect on wood delignification (Lundqvist et al., 2005). Thus, acid leaching is advantageous for subsequent pulping.
Acid leaching removed manganese from $60.2 \mathrm{mg} / \mathrm{kg}$ to 29.3 $\mathrm{mg} / \mathrm{kg}$ for bamboo and from $16.8 \mathrm{mg} / \mathrm{kg}$ to $4.7 \mathrm{mg} / \mathrm{kg}$ for wood chips. Manganese has deleterious effects on elemental chlorine free (ECF) and total chlorine free (TCF) bleaching since they catalyze decomposition of oxygen based bleaching reagents.

Manganese also catalyzes cellulose depolymerization reactions during oxygen delignification and alkaline peroxide bleaching stages, and degrades hydrogen peroxide solutions (Ulmgren, 1997).

Acid leaching also removed part of magnesium was from bamboo (22.2\%) and wood chips (31.1\%). Magnesium protects carbohydrate degradation during oxygen delignification and peroxide bleaching (Kolar, 1997).

\section{Pulping}

Acid leached wood and bamboo chips were cooked by kraft process with varying alkali charge. The results are compared with the non-acid leached wood and bamboo chips data (Table II). Acid leached chips showed higher screen pulp yield and lower rejects than the non-leached counterpart. At the $18 \%$ active alkali charge, screened pulp yield was $33.9 \%$

Table II. Effect of acid leaching on the pulping of hardwood and bamboo

\begin{tabular}{|c|c|c|c|c|c|c|c|c|c|}
\hline & \multirow{3}{*}{$\begin{array}{c}\text { Alkali } \\
\text { charge } \\
(\%)\end{array}$} & \multicolumn{3}{|c|}{ Without leaching } & \multicolumn{5}{|c|}{ On leaching } \\
\hline & & \multicolumn{3}{|c|}{ Yield $(\%)$} & \multirow{2}{*}{$\begin{array}{l}\text { Kappa } \\
\text { number }\end{array}$} & \multicolumn{3}{|c|}{ Yield (\%) } & \multirow{2}{*}{$\begin{array}{l}\text { Kappa } \\
\text { number }\end{array}$} \\
\hline & & Screened & Reject & Total & & Screened & Reject & Total & \\
\hline \multirow[t]{3}{*}{ Wood } & 16 & 34.8 & 3.1 & 37.9 & 16.1 & 35.2 & 2.7 & 37.9 & 15.1 \\
\hline & 18 & 33.9 & 2.2 & 36.7 & 15.4 & 34.7 & 0.7 & 35.4 & 14.0 \\
\hline & 20 & 33.0 & 1.5 & 34.5 & 12.3 & 33.9 & 0 & 33.9 & 12.0 \\
\hline \multirow[t]{3}{*}{ bamboo } & 16 & 39.8 & 0 & 39.8 & 12.5 & 39.9 & 0 & 39.9 & 11.9 \\
\hline & 18 & 35.3 & 0 & 37.4 & 10.2 & 37.3 & 0 & 37.4 & 9.6 \\
\hline & 20 & 34.6 & 0 & 34.6 & 9.3 & 34.2 & 0 & 34.2 & 9.4 \\
\hline
\end{tabular}


and $35.3 \%$ for acid leached hardwood and bamboo, respectively. The pulp yields were lower than expected, which due to inferior quality of chips. The screened yields were $0.4 \%$ and 2.1\% higher than non-leached chips. Acid leached hardwood had lower reject than non-leached hardwood. Acid leaching reduced kappa number(Table II). Similar results were obtained for birch wood chips (Lundqvist et al., 2006). Moreira et al. (2008) also showed that acid treatment improved delignification rate. Acidic leaching of both the chips prior to cooking resulted in a significant increase in the rate of delignification at a lower alkali charge . But it had no effect as it approaches the residual delignification phase (Fig. 1). The screened yield gain and improved delignification can be explained by the fact that acid leaching removed material, which would otherwise be removed during cooking.

\section{Papermaking properties of unbleached pulp}

The pulp obtained from acid leached and non-leached bamboo and hardwood chips were beaten to drainage resistance ( $\left.{ }^{\mathrm{O}} \mathrm{SR}\right) 25$ and papermaking properties were determined. The results are given in Table III. There was no significant difference observed between pulps obtained from acid leached and non-leached chips. At $18 \%$ active alkali charge, acid leaching increased tensile index by $3.3 \%$ for hardwood while decreased tear index by $12.7 \%$. On the other hand, no difference in tensile index was found for bamboo pulp.

\section{Bleaching}

As shown in Table IV, acid leaching of both wood and bamboo chips had positive effects on bleaching, especially with

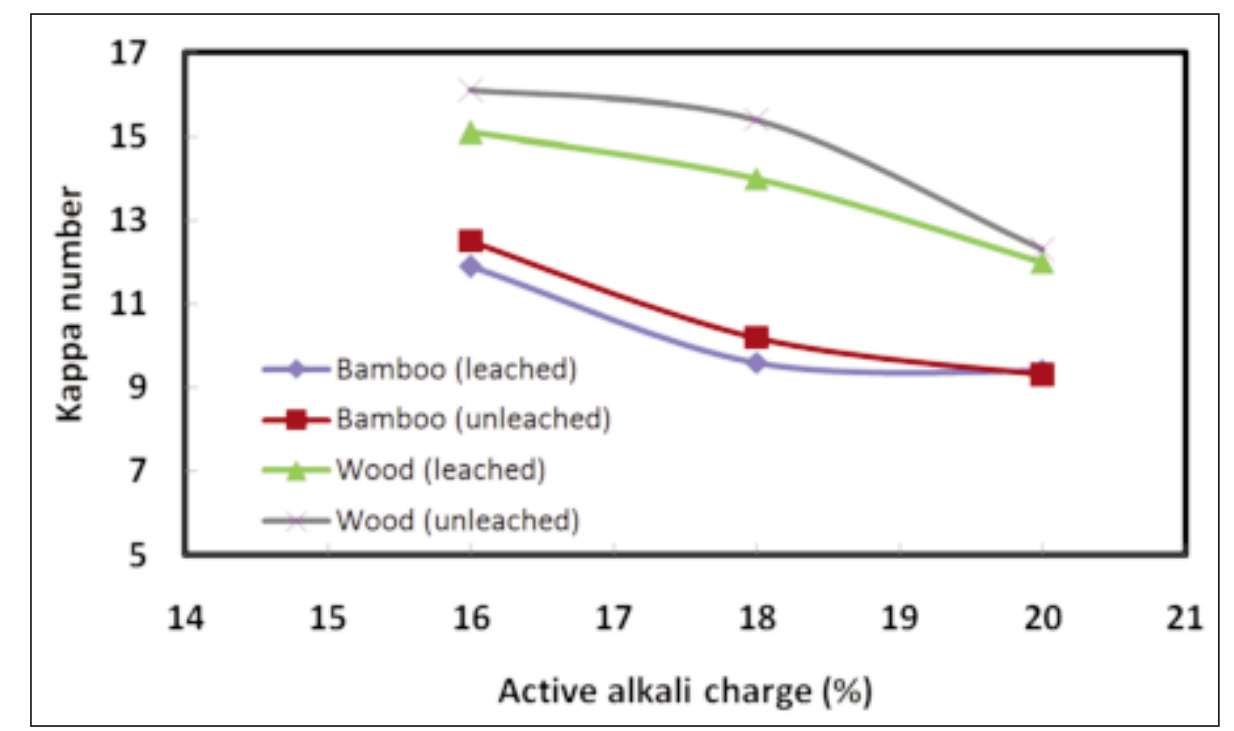

Fig. 1. Effect of acid leaching on the delignification of bamboo and hardwood chips by kraft process

Table III. Effect of acid leaching on the papermaking properties of unbleached pulp

\begin{tabular}{|c|c|c|c|c|c|c|c|}
\hline & \multirow{2}{*}{$\begin{array}{c}\text { Alkali } \\
\text { charge } \\
(\%)\end{array}$} & \multicolumn{3}{|c|}{ Without leaching } & \multicolumn{3}{|c|}{ On leaching } \\
\hline & & $\begin{array}{c}\text { Tensile index } \\
(\mathrm{N} . \mathrm{m} / \mathrm{g})\end{array}$ & $\begin{array}{l}\text { Burst index } \\
\left(\mathrm{kPa} \cdot \mathrm{m}^{2} / \mathrm{g}\right)\end{array}$ & $\begin{array}{l}\text { Tear index } \\
\left(\mathrm{mN} \cdot \mathrm{m}^{2} / \mathrm{g}\right)\end{array}$ & $\begin{array}{c}\text { Tensile index } \\
(\mathrm{N} . \mathrm{m} / \mathrm{g})\end{array}$ & $\begin{array}{l}\text { Burst index } \\
\left(\mathrm{kPa} \cdot \mathrm{m}^{2} / \mathrm{g}\right)\end{array}$ & $\begin{array}{l}\text { Tear index } \\
\left(\mathrm{mN} \cdot \mathrm{m}^{2} / \mathrm{g}\right)\end{array}$ \\
\hline \multirow[t]{3}{*}{ Wood } & 16 & 33.3 & 2.5 & 9.8 & 34.5 & 2.5 & 9.7 \\
\hline & 18 & 33.1 & 2.4 & 10.2 & 34.2 & 2.4 & 8.9 \\
\hline & 20 & 33.0 & 2.6 & 9.7 & 34.0 & 2.3 & 8.5 \\
\hline \multirow[t]{3}{*}{ bamboo } & 16 & 24.4 & 2.3 & 17.4 & 24.3 & 2.1 & 17.2 \\
\hline & 18 & 24.8 & 2.1 & 17.8 & 24.9 & 2.2 & 16.8 \\
\hline & 20 & 24.4 & 2.2 & 17.5 & 24.6 & 2.2 & 16.4 \\
\hline
\end{tabular}


Table IV. Effect of acid leaching on the bleaching of bamboo and wood pulp

\begin{tabular}{|c|c|c|c|c|c|c|}
\hline & \multicolumn{3}{|c|}{ Without leaching } & \multicolumn{3}{|c|}{ On leaching } \\
\hline & \multicolumn{2}{|c|}{ Brightness $(\%)$} & \multirow{2}{*}{$\begin{array}{c}\text { Viscosity } \\
\text { mPa.s }\end{array}$} & \multicolumn{2}{|c|}{ Brightness $(\%)$} & \multirow[t]{2}{*}{ Viscosity $\mathrm{mPa} . \mathrm{s}$} \\
\hline & Unbleached & Bleached & & Unbleached & Bleached & \\
\hline Wood & 16.4 & 75.5 & 10.1 & 16.2 & 76.2 & 12.1 \\
\hline Bamboo & 23.2 & 85.4 & 12.1 & 23.3 & 86.5 & 12.3 \\
\hline
\end{tabular}

regard to brightness and final pulp viscosity. Unbleached pulp brightness was not improved on acid leaching. But acid leaching improved pulp brightness by $1 \%$ and $1.1 \%$ for hardwood and bamboo, respectively, using same $\mathrm{ClO}_{2}$ charge. DelAntonio et al. (2011) also observed positive effects of acid leaching on pulp brightness of two eucalyptus species. Moreira et al. (2008) also showed that the pulp from acid leached chips showed improved performance during bleaching over the reference pulp. Acid leaching improved pulp viscosity from 10.1 to $12.1 \mathrm{mPa}$.s for hardwood and from 12.1 to $12.3 \mathrm{mPa}$.s from bamboo. Lundquist et al. (2006) showed that acid leaching increased pulp viscosity for birch wood while the viscosity of eucalyptus pulp did not increase.

\section{Conclusions}

Acid leaching of calcium is more difficult with bamboo chips compared to hardwood chips. Potassium, magnesium and manganese are leached similarly for both the chips. Acid leaching significantly improved delignification in subsequent kraft pulping. Acid leaching also reduced screening reject and slightly improved pulp yield. Improved pulp brightness and viscosity were observed on acid leached hardwood and bamboo chips. From the above results, it can be concluded that acid leaching of bamboo and hardwood chips prior to pulping is advantageous kraft pulping.

\section{Acknowledgement}

Authors with thank BCSIR for providing necessary fund to carry out the research.

\section{References}

Axegard P. - Ecocyclic Pulp Mill - "KAM", KAM report A100, p. 83-89, available from STFI-Packforsk AB (2003).

Colodette JL, Rothenberg S and Dence CW (1989a), Factors Affecting Hydrogen Peroxide Stability in the
Brightening of Mechanical and Chemimechanical Pulps. 2. Hydrogen Peroxide Stability in the Presence of Sodium Silicate, Journal of Pulp and Paper Science 15: 3- 10 .

Colodette JL, Rothenberg S and Dence CW (1989b), Factors Affecting Hydrogen Peroxide Stability in the Brightening of Mechanical and Chemimechanical Pulps. 4. Effect of Transition Metals in Norway Spruce TMP on Hydrogen Peroxide Stability, Journal of Pulp and Paper Science 15: 79 -83.

DelAntonio NRD, Colodette JL, Mounteer AH, Silva CM, Gomes VJ and Martino DC (2011), Influence of acid leaching of chips on eucalypt pulp production: Environmental and process performance. Nordic Pulp and Paper Research Journal 26(2): 205-213.

Humar M, Pohleven F and Šentjurc M (2004), Effect of oxalic, acetic acid, and ammonia on leaching of $\mathrm{Cr}$ and $\mathrm{Cu}$ from preserved wood, Wood Science and Technology 37(6): 463-473.

Kolar J (1997), Mechanism of autoxidative degradation of cellulose, Restaurator 18(4): 163-176.

Lundqvist F, Brelid H, Saltberg A, Gellerstedt G and Tomani P (2006), Removal of non-process elements from hardwood chips prior to kraft cooking, Appita Journal 59(6): 493-499.

Lundqvist F, Brelid H, Eliasson A, Tomani P, Wadsborn R (2005), Improved Process Efficiency by Pre-Treatment of Chips, 8th International Conference on New Available Technologies, Stockholm, p. 5.

Moreira E, Colodette JL, Gomide JL, Oliveira RC, Regazzi AJ and Sacon VM (2008), Effect of acid leaching of eucalyptus wood on kraft pulping and pulp bleachability, Journal of wood chemistry and technology 28(2): 137-152. 
Rocha T, Duarte A, Duarte R, Neto CP, Sampaio R, Oliveira $\mathrm{J}$ and Caldeira MT (1998), Analysis of NPE of the main process streams of an Eucalyptus bleached kraft pulp mill: preliminary results, Proc. Fifth European workshop on lignocellulosic and pulp, Advances in lignocellulosics chemistry for ecologically friendly pulping and bleaching technologies, University of Aveiro, Portugal, pp. 345 - 348.

Santos RB, Gomide JL and Hart PW (2015), Impact of wood chips leaching pretreatment on wood chemical composition, TAPPI Journal 14(1): 9-14.

Silva MR, Peixoto MAL and Colodette JL (2002), 35 Congresso Anual de Celulose e Papel, ABTCP, São Paulo, p. 1.

Taylor K and McGuffie B (2006), Investigation of nonprocess elements chemistry at Elk Falls mill - green liquor clarifier and lime cycle, PAPTAC, Parksville Conference.
Tran H and Vakkilainen EK (2007), Advances in the Kraft chemical recovery process, 3rd ICEP international colloquium on eucalyptus pulp, Belo Horizonte, Brazil, pp. 4-7.

Ulmgren P (1987), The removal of aluminium from the recovery system of a closed kraft pulp mill, Nordic Pulp and Research Journal 1: 4-9.

Ulmgren P (1997), Non-process elements in a bleached kraft pulp mill with a high degree of system closure - state of the art, Nordic Pulp Paper Research Journal 12(1): $32-41$.

Verrill CL and Frederick JWJ (2005), Engineering, Pulping and Environmental Conference Proceedings, TAPPI PRESS, Atlanta, p.1.

Received: 31 May 2016; Revised: 13 June 2016; Accepted: 28 July 2016. 